\title{
English Language Learner Boys and Girls Reading and Math Achievement as a Function of Early-Exit and Late-Exit Bilingual Programs: A Multiyear, Statewide Analysis
}

\author{
Rosa Maria Martinez, ${ }^{1}$ John R. Slate, ${ }^{2}$ and Cynthia Martinez-Garcia ${ }^{2}$ \\ ${ }^{1}$ Huntsville Independent School District, Huntsville, TX 77320, USA \\ ${ }^{2}$ Sam Houston State University, Huntsville, TX 77341, USA \\ Correspondence should be addressed to John R. Slate; profslate@aol.com
}

Received 1 July 2014; Revised 13 November 2014; Accepted 20 November 2014; Published 18 December 2014

Academic Editor: Connie M. Wiskin

Copyright (C) 2014 Rosa Maria Martinez et al. This is an open access article distributed under the Creative Commons Attribution License, which permits unrestricted use, distribution, and reproduction in any medium, provided the original work is properly cited.

\begin{abstract}
We examined the reading and math performance of English Language Learner boys and girls in Grades 3, 4, 5, and 6 as a function of early-exit or late-exit transitional bilingual education program. Texas Assessment of Knowledge and Skills Reading and Mathematics scores of all English Language Learner boys and girls who were enrolled in either early-exit or late-exit bilingual education programs were analyzed for the 2008-2009, 2009-2010, and 2010-2011 school years. Results were not consistent across reading and math, across the 4 grade levels, and across the 3 school years. On the TAKS Reading test, 5 instances were present in which statistically significant differences were revealed for boys and 11 for girls. On the TAKS Mathematics test, 8 statistically significant results were revealed for boys and 6 for girls. These statistically significant differences were not consistently in favor of either the early-exit or the late-exit bilingual education programs. Moreover, the differences that were present reflected small to trivial effect sizes. As such, neither the early-exit nor the late-exit bilingual education program was demonstrated to be more effective than its counterpart.
\end{abstract}

\section{Introduction}

Transitional bilingual education can be an early-exit or a lateexit bilingual program designed to help students acquire and improve English skills $[1,2]$ and to encourage a language shift for language minority students [3]. In the United States, the transitional bilingual education program is the instructional model most utilized in schools for English language development [2]. The transitional bilingual education instructional model provides students' instruction in the first language in literacy and content areas and transition instruction to English [2].

In an early-exit bilingual program, students study subject matter in their primary language and English [4]. The primary purpose of the program is to facilitate the transition of English Language Learners to an English-only instructional classroom, while receiving academic subject instruction in the primary language to the extent necessary $[1,5]$. In earlyexit bilingual programs, students transition into English-only classroom within 2 to 3 years of achieving English language proficiency and all students are of the same linguistic background $[2,6]$.

Students in transitional bilingual programs learn to read in their home language and then in English [4]. The duration of the program and amount of native language instruction vary in each classroom, school, and district. Most campuses follow the 90/10 model, in which students receive native language instruction $90 \%$ of the time and English instruction $10 \%$ of the time. Spanish instruction decreases $10 \%$ each year and English instruction increases $10 \%$ each year [5, 7]. Instruction in the first language is phased out quickly and typically students transition into the mainstream program by the end of Grade 1 or Grade 2 [1]. This program model is the most common model for instructional support of English Language Learners in the United States [2]. Usually English Language Learners are placed in early-exit bilingual programs for over a 2- to 4-year period [2-4]. Ramirez [4] and Tong et al. [2] reported that students in early-exit bilingual programs 
were reclassified as English proficient and were mainstreamed by the end of Grade 1 or Grade 2. As such, early-exit bilingual education constitutes a subtractive language approach where a disproportionate number of children fall behind in class [8].

Late-exit bilingual education programs provide instruction in students' primary languages from kindergarten through Grade 6, along with balanced second language academic instruction $[3,4,8]$. Opportunities for instruction in the first language are extended throughout the elementary school years and students are introduced to English in Grade 2 or $3[3,8]$. Furthermore, the student's primary language is used for instructional purposes for approximately $40 \%$ to $50 \%$ of the instructional day through Grade 6 [4]. Students taught in their native language over a period of time allow content language to develop in their native language. Having a strong foundation in the native language means that content skills will be transferred more effectively into the second language and result in the development of a solid foundation of knowledge and skills [8]. Vygotsky [9] commented, "Success in learning a foreign language is contingent on a certain degree of maturity in the native language" (p. 195). Vygotsky [9] noted that a child can transfer the system of meaning used with the native language to the new language. Lateexit bilingual programs provide a balanced native language support through Grade 6. The greater amount of the native language instruction support provided was related to higher levels of academic achievement in the second language in each subsequent academic school year [3].

One model, in late-exit bilingual programs, introduces the first language and the second language reading in the same year. A second model introduces reading in the first language taught first and the second language reading is introduced in Grade 2 or 3 [3]. Consequently, second language learners maintain their academic success at the secondary level, even when the instruction in middle school and high school is delivered through the second language. Positively, late-exit bilingual programs allow for the academic knowledge learned in the first language to transfer to academic knowledge in the second language [10]. Therefore, the more the high-quality education the students received in first language, the deeper their conceptual level of knowledge across both languages. Late-exit programs might keep English Language Learners segregated from English speakers; however, the students are still able to build the self-confidence and academic skills needed to succeed in school because of their academic growth in the first language [10]. Cummins [11] ascertained that the benefits of a late-exit bilingual program are due to the affirmation of the English Language Learner's cultural identity.

In a study conducted by Ramirez et al. [12] about three program types (i.e., structured English immersion, earlyexit transitional bilingual education, and late-exit transitional bilingual program), statistically significant differences among these three programs were present in the language spoken in the classroom. Interestingly, statistically significant differences were not revealed in the instructional practices utilized in the classroom. The researchers revealed that, after 2 years, English Language Learners in immersion programs and
English Language Learners in early-exit programs performed equally well in English, reading, and math by Grade 3. Students in late-exit programs received a substantial portion of instruction in the primary language (40\%) and continued to increase their achievement in content area subjects [12]. Conversely, Tong et al. [6] examined oral language development to promote academic oral English development. These researchers examined the outcome differences between structured English immersion and transitional bilingual education programs. The interventions used by the teachers significantly accelerated oral language development in English Language Learners who received best practices in both the structured English immersion and transitional bilingual education [6].

Notwithstanding, in a second study, Tong et al. [2] conducted a longitudinal study of English intervention in a developmental bilingual education program. In a developmental bilingual education program, the aim for bilingualism is communicating in both languages and biliteracy, reading, and writing in both languages. The goals in developmental bilingual education programs are to obtain (a) "full academic language proficiency in the first language and second language and (b) high levels of academic performance and cross-cultural understanding" [2, p. 501]. Other terms in the research literature for developmental bilingual education are "one-way dual language, one-way developmental, maintenance bilingual, and late-exit" programs [2, p. 51]. The researchers concluded that quality developmental bilingual education intervention positively promoted bilingualism and biliteracy and confirmed that years were required for English Language Learners to master English language proficiency for academic success [2].

Language for females and males can have different meanings for different groups $[13,14]$. Eckert and McConnell-Ginet [15] argued that separating children in same-sex groups has important implications in how boys and girls socialize differently. Within same-sex groups, children develop "different behaviors, different norms, and even different understandings of the world" (p. 24). As such, boys and girls develop different "verbal cultures," different ways of interacting with each other [15, p. 24]. Furthermore, parents are inclined to use more diminutives (e.g., doggie and kitty) and more inner state words (e.g., happy and sad) when speaking to baby girls than they do for baby boys. Similarly, parents are more inclined to use direct prohibitive statements (e.g., no, do not do that) with baby boys than with baby girls [15].

Neuroscientists have discovered that male and female brains process language differently. One gender difference is that the corpus callosum that connects the two hemispheres in the brain is larger and thicker in female brains. This difference may imply that messages travel faster between the two cerebral hemispheres, thus contributing to girls acquiring spoken language easier and faster than most boys [16]. Gardner and Desrochers [14] noted that girls achieved higher levels of language proficiency than boys. A closer examination of language development between girls and boys may yield implications to different instructional practices for each group. 
1.1. Statement of the Problem. The number of students identified as English Language Learners has increased progressively over the last 26 years in Texas. In 1975, the state of Texas reported that a total of 25,000 English Language Learners were enrolled in school. In contrast, 775,432 English Language Learners were enrolled in Texas public schools in the 2007-2008 school year, accounting for $16.6 \%$ of the total student population in Texas public schools [17]. Furthermore, over 120 languages are represented in Texas public schools as reported in the Public Education Information Management System data for English Language Learners. Of the students speaking a language other than English in Texas public schools, 91\% speak Spanish, 1.90\% speak Vietnamese, 0.59\% speak Arabic, and 0.49\% speak Urdu [18]. As such, Texas educators are faced with the decision of supporting the first language or English in the role of academic and cognitive development for English Language Learners. Given that language development differs between boys and girls, an indepth analysis of transitional bilingual education programs may yield implications for different instructional practices for each group.

1.2. Purpose of the Study. In this research investigation, the extent to which boys and girls responded differentially to early-exit and to late-exit transitional bilingual education programs was examined. The reading and math performance of English Language Learner boys and girls in Grades 3, 4, 5, and 6 were analyzed separately. Furthermore, four school years of statewide data were examined to ascertain the extent to which trends might be present in the performance of English Language Learner boys and girls. Because the Texas Education Code, $\$ 29.051$, contends that "public school classes in which instruction are [sic] given only in English are often inadequate for the education of" English Language Learners $[19$, p. 39], we were interested in addressing this issue for English Language Learner boys and girls.

1.3. Significance of the Study. Given the growing number of English Language Learners, both nationally and particularly in the State of Texas, research into the efficacy of bilingual education programs is sorely needed. Furthermore, under the No Child Left Behind Act, English language proficiency standards and state assessments are mandated in every state. As such, results of this study could be informative for policymakers and educational leaders alike. Should English Language Learner boys and girls respond in a differential manner by grade level to early-exit or to late-exit transitional bilingual education programs, changes could be made to existing transitional bilingual education programs.

1.4. Research Questions. For this investigation of the academic achievement of English Language Learners based on participation in a traditional early-exit or a late-exit bilingual program, two research questions were addressed: (a) What is the difference in reading achievement for Grades 3, 4, 5, and 6 English Language Learner boys and girls who participated in early-exit and late-exit bilingual programs? And (b) What is the difference in the math achievement for Grades 3, 4,
5, and 6 English Language Learner boys and girls who participated in early-exit and late-exit bilingual programs? Each question was repeated for the 3 school years of statewide data (i.e., 2008-2009, 2009-2010, and 2010-2011) analyzed in this investigation.

\section{Method}

2.1. Selection of Participants. For the purpose of this study, archival data were requested and received from the Texas Education Agency Public Education Information Management System for English Language Learner boys and girls in Grades 3, 4, 5, and 6 who were enrolled in a bilingual education program in Texas public schools for the 2008-2009, 2009-2010, and 2010-2011 school years. The data we received were cross-sectional data and not longitudinal data. As a result, the students whose data were analyzed were different students from grade level to grade level. The students whose data were analyzed herein were English Language Learner boys and girls who were enrolled in Texas public schools and who participated in either an early-exit or a late-exit bilingual program. The particular type of bilingual education program was a function of the school system in which students were enrolled. As such, students were not randomly assigned but rather were enrolled in the bilingual education program type that was implemented in their particular school district. Students whose reading and math scores were not analyzed in this research investigation were English Language Learners who were enrolled in either charter or private schools.

2.2. Instrumentation. The dependent variables we analyzed in this research study were Texas Assessment of Knowledge and Skills (TAKS) Reading and Mathematics scores for 3 school years (i.e., 2008-2009, 2009-2010, and 2010-2011). The test score data that were analyzed were test scores from the English version of the TAKS. The Texas Education Agency Public Education Information Management System gathers extensive data on students, teachers, and schools and makes these data available upon request. Extensive information regarding the psychometric qualities of the TAKS Reading and Mathematics assessments can be located on the Texas Education Agency website.

2.3. Definition of Relevant Terms. The first term of note is that of what constitutes an English Language Learner. In Texas, the Commissioner's Rules Concerning State Plan for Educating English Language Learners Texas Administrative Code, $\$ 89.1203$, defines students who are English Language Learners as follows: "A person who is in the process of acquiring English and has another language as the first native language" $[19$, p. 17]. Another important definition for this research study is that of the transitional early-exit bilingual education program, which is defined by Texas Education Agency as follows.

Transitional bilingual/early-exit is a bilingual program model that serves a student identified as limited English proficient in both English and Spanish, or another language, and transfers the student 
to English-only instruction. This model provides instruction in literacy and academic content areas through the medium of the student's first language, along with instruction in English oral and academic language development. Nonacademic subjects such as art, music, and physical education may also be taught in English. Exiting of a student to an all-English program of instruction will occur no earlier than earlier than two years or later than five years after the student enrolls in school ([20,\$89.1210(d) (1)]; [19, p. 22]).

Finally, a third important definition is that of the transitional late-exit bilingual education program, which is defined by the Texas Education Agency as follows.

Transitional bilingual/late-exit is a bilingual program model that serves a student identified as limited English proficient in both English and Spanish, or another language, and transfers the student to English-only instruction. Academic growth is accelerated through cognitively challenging academic work in the student's first language along with meaningful academic content taught through the student's second language, English. The goal is to promote high levels of academic achievement and full academic language proficiency in the student's first language and English. A student enrolled in a transitional bilingual/late-exit program is eligible to exit the program no earlier than six years or later than seven years after the student enrolls in school $([20, \$ 89.1210$ (d) (2)]; [19, p. 22]).

\section{Results}

3.1. Checks of Underlying Assumptions for Statistical Procedures. To address each research question, an analysis of variance (ANOVA) procedure was calculated. Its underlying assumptions of data normality and homogeneity of variance were checked for each instance of its use. For the majority of cases, the underlying assumptions were met [21]. As such, the ANOVA procedure was used to determine the extent to which statistically significant differences were present in reading and math performance for English Language Learner boys and girls as a function of type of bilingual program. Because the TAKS tests are not comparable across grade levels, separate ANOVAs were conducted for each grade level for each year.

3.2. Reading Results for Grade 3. With respect to the 2009 school year administration for boys, a statistically significant difference was not revealed in the average TAKS Reading raw scores as a function of early-exit versus late-exit bilingual programs, $F(1,24306)=0.03, P=.86$. Grade 3 boys in the early-exit and late-exit bilingual programs had commensurate TAKS Reading raw scores. A statistically significant difference, however, was revealed in the average TAKS Reading raw scores for girls, $F(1,23484)=68.00, P<.001$, partial $\eta^{2}=.003$, trivial effect size [22], as a function of
TABLE 1: Descriptive statistics for the 2009, 2010, and 2011 TAKS Reading scores for Grade 3 boys and girls by bilingual education program.

\begin{tabular}{|c|c|c|c|}
\hline $\begin{array}{l}\text { Year, gender, and bilingual } \\
\text { education program }\end{array}$ & $n$ & M & SD \\
\hline \multicolumn{4}{|l|}{2009} \\
\hline \multicolumn{4}{|l|}{ Boys } \\
\hline Early-exit & 14,850 & 26.84 & 7.48 \\
\hline Late-exit & 9,458 & 26.82 & 7.35 \\
\hline \multicolumn{4}{|l|}{ Girls } \\
\hline Early-exit & 14,104 & 27.82 & 7.08 \\
\hline Late-exit & 9,382 & 28.58 & 6.53 \\
\hline \multicolumn{4}{|l|}{2010} \\
\hline \multicolumn{4}{|l|}{ Boys } \\
\hline Early-exit & 14,708 & 27.00 & 7.50 \\
\hline Late-exit & 9,140 & 26.91 & 7.55 \\
\hline \multicolumn{4}{|l|}{ Girls } \\
\hline Early-exit & 13,698 & 28.01 & 7.07 \\
\hline Late-exit & 8,873 & 28.39 & 6.69 \\
\hline \multicolumn{4}{|l|}{2011} \\
\hline \multicolumn{4}{|l|}{ Boys } \\
\hline Early-exit & 14,904 & 26.50 & 7.74 \\
\hline Late-exit & 7,298 & 27.12 & 7.28 \\
\hline \multicolumn{4}{|l|}{ Girls } \\
\hline Early-exit & 14,362 & 27.70 & 7.11 \\
\hline Late-exit & 7,123 & 28.58 & 6.64 \\
\hline
\end{tabular}

early-exit versus late-exit program. Grade 3 girls in the lateexit program had a higher average TAKS Reading raw score than did Grade 3 girls in the early-exit program. Descriptive statistics for this analysis are presented in Table 1.

Concerning the 2010 school year for boys, a statistically significant difference was not present for Grade 3 boys in their TAKS Reading raw scores as a function of bilingual program enrollment, $F(1,23846)=0.75, P=.39$. Grade 3 boys in both early-exit and late-exit bilingual programs had comparable TAKS Reading scores. For girls, however, a statistically significant difference was present, $F(1,22569)=16.92$, $P<.001$, partial $\eta^{2}=.001$, trivial effect size [22], as a function of early-exit versus late-exit program. Grade 3 girls in the lateexit bilingual programs had higher average TAKS Reading scores than did Grade 3 girls in the early-exit bilingual programs. Descriptive statistics for this analysis are presented in Table 1.

Regarding the 2011 school year, a statistically significant difference was revealed in Grade 3 boys' average TAKS Reading raw scores, $F(1,22200)=33.40, P=.001$, partial $\eta^{2}=$ .002 , trivial effect size [22], as a function of early-exit versus late-exit program. Grade 3 English Language Learner boys in the late-exit program had a statistically significantly higher average TAKS Reading raw score than did Grade 3 English Language Learner boys in the early-exit program. A statistically significant difference was also yielded for Grade 3 girls' average TAKS Reading raw scores, $F(1,21483)=76.33$, 
TABLE 2: Descriptive statistics for the 2009, 2010, and 2011 TAKS Reading scores for grade 4 boys and girls by bilingual education program.

\begin{tabular}{|c|c|c|c|}
\hline $\begin{array}{l}\text { Year, gender, and bilingual } \\
\text { education program }\end{array}$ & $n$ & M & SD \\
\hline \multicolumn{4}{|l|}{2009} \\
\hline \multicolumn{4}{|l|}{ Boys } \\
\hline Early-exit & 11,433 & 28.20 & 8.91 \\
\hline Late-exit & 9,435 & 28.14 & 8.68 \\
\hline \multicolumn{4}{|l|}{ Girls } \\
\hline Early-exit & 10,475 & 29.76 & 8.33 \\
\hline Late-exit & 8,983 & 30.00 & 7.86 \\
\hline \multicolumn{4}{|l|}{2010} \\
\hline \multicolumn{4}{|l|}{ Boys } \\
\hline Early-exit & 11,798 & 28.31 & 8.49 \\
\hline Late-exit & 7,526 & 28.71 & 8.16 \\
\hline \multicolumn{4}{|l|}{ Girls } \\
\hline Early-exit & 10,638 & 29.00 & 8.17 \\
\hline Late-exit & 7,529 & 30.02 & 7.63 \\
\hline \multicolumn{4}{|l|}{2011} \\
\hline \multicolumn{4}{|l|}{ Boys } \\
\hline Early-exit & 12,016 & 28.08 & 8.76 \\
\hline Late-exit & 6,773 & 28.96 & 8.20 \\
\hline \multicolumn{4}{|l|}{ Girls } \\
\hline Early-exit & 10,882 & 28.70 & 8.54 \\
\hline Late-exit & 6,530 & 30.04 & 7.82 \\
\hline
\end{tabular}

$P=.001$, partial $\eta^{2}=.004$, trivial effect size, as a function of early-exit versus late-exit program. Grade 3 English Language Learner girls in the late-exit program had a statistically significantly higher average TAKS Reading raw score than did Grade 3 English Language Learner girls in the early-exit program. Descriptive statistics for this analysis are presented in Table 1.

3.3. Reading Results for Grade 4. Regarding the 2009 school year, a statistically significant difference was not present in Grade 4 English Language Learner boys' average TAKS Reading raw scores, $F(1,20866)=0.24, P=.63$, as a function of early-exit versus late-exit program. A statistically significant difference was yielded for Grade 4 English Language Learner girls, $F(1,19456)=4.22, P=.04$, partial $\eta^{2}=.001$, trivial effect size, as a function of early-exit versus late-exit program. Grade 4 English Language Learner girls in the late-exit program had a higher average TAKS Reading raw score than did Grade 4 English Language Learner girls in the early-exit program. Descriptive statistics for this analysis are presented in Table 2.

With respect to the 2010 school year, a statistically significant difference was present in Grade 4 boys' average TAKS Reading raw scores, $F(1,19322)=10.63, P=.001$, partial $\eta^{2}=.002$, trivial effect size, and in Grade 4 girls' average TAKS Reading raw scores, $F(1,18165)=72.11, P=.001$, partial $\eta^{2}=.004$, trivial effect size, as a function of early-exit versus late-exit program. Grade 4 English Language Learner boys and girls in the late-exit program had a higher average TAKS Reading raw score than did Grade 4 English Language Learner boys and girls in the early-exit program. Descriptive statistics for this analysis are presented in Table 2.

With regard to the 2011 school year, a statistically significant difference was present in Grade 4 boys' TAKS Reading scores, $F(1,18787)=45.48, P=.001$, partial $\eta^{2}=.002$, trivial effect size, and in Grade 4 girls' TAKS Reading scores, $F(1,17410)=106.31, P=.001$, partial $\eta^{2}=.006$, trivial effect size, as a function of early-exit versus late-exit program. Grade 4 English Language Learner boys and girls in the lateexit program had higher average TAKS Reading raw scores than did Grade 4 English Language Learner boys and girls in the early-exit program.

Descriptive statistics for this analysis are presented in Table 2.

3.4. Reading Results for Grade 5. Regarding the 2009 school year, a statistically significant difference was not present in Grade 5 boys' TAKS Reading raw scores, $F(1,14544)=0.18$, $P=.68$, as a function of early-exit versus late-exit program. Similar TAKS Reading scores were present for Grade 5 English Language Learner boys in both the early-exit and the late-exit bilingual programs. A statistically significant difference was present for Grade 5 girls' TAKS Reading scores, $F(1,13815)=12.26, P=.001$, partial $\eta^{2}=.002$, trivial effect size, as a function of early-exit versus late-exit programs. Grade 5 English Language Learner girls in late-exit programs had a higher average TAKS Reading score than did Grade 5 English Language Learner girls in early-exit programs. Descriptive statistics for this analysis are presented in Table 3.

With respect to the 2010 school year, a statistically significant difference was present in Grade 5 boys TAKS Reading raw scores, $F(1,15092)=8.11, P=.004$, partial $\eta^{2}=.001$, trivial effect size, as a function of early-exit versus late-exit program. A statistically significant difference was also yielded for Grade 5 girls TAKS Reading raw scores, $F(1,13755)=9.54, P=.001$, partial $\eta^{2}=.001$, trivial effect size, as a function of early versus late-exit program. Grade 5 English Language Learner boys and girls in lateexit bilingual programs had lower average TAKS Reading raw scores than their counterparts in early-exit programs. Descriptive statistics for this analysis are presented in Table 3.

Regarding the 2011 school year, a statistically significant difference was not revealed in Grade 5 boys' TAKS Reading raw scores, $F(1,13592)=3.05, P=.08$, as a function of early-exit versus late-exit program. A statistically significant difference was present, however, for Grade 5 girls' TAKS Reading raw scores, $F(1,12619)=42.49, P=.001$, partial $\eta^{2}=.003$, trivial effect size, as a function of early versus lateexit program. Grade 5 English Language Learner boys in lateexit and in early-exit bilingual programs had commensurate average TAKS Reading raw scores. Grade 5 English Language Learner girls in late-exit bilingual programs had higher average TAKS Reading raw scores than did Grade 5 English 
TABLE 3: Descriptive statistics for the 2009, 2010, and 2011 TAKS Reading scores for Grade 5 boys and girls by bilingual education program.

\begin{tabular}{|c|c|c|c|}
\hline $\begin{array}{l}\text { Year, gender, and bilingual } \\
\text { education program }\end{array}$ & $n$ & $\mathrm{M}$ & SD \\
\hline \multicolumn{4}{|l|}{2009} \\
\hline \multicolumn{4}{|l|}{ Boys } \\
\hline Early-exit & 7,563 & 26.05 & 9.13 \\
\hline Late-exit & 6,983 & 25.98 & 9.23 \\
\hline \multicolumn{4}{|l|}{ Girls } \\
\hline Early-exit & 6,967 & 27.16 & 9.02 \\
\hline Late-exit & 6,850 & 27.69 & 8.84 \\
\hline \multicolumn{4}{|l|}{2010} \\
\hline \multicolumn{4}{|l|}{ Boys } \\
\hline Early-exit & 7,842 & 27.77 & 9.38 \\
\hline Late-exit & 7,252 & 28.20 & 8.88 \\
\hline \multicolumn{4}{|l|}{ Girls } \\
\hline Early-exit & 7,033 & 29.11 & 9.22 \\
\hline Late-exit & 6,724 & 29.58 & 8.52 \\
\hline \multicolumn{4}{|l|}{2011} \\
\hline \multicolumn{4}{|l|}{ Boys } \\
\hline Early-exit & 8,118 & 28.20 & 9.35 \\
\hline Late-exit & 5,476 & 28.48 & 8.90 \\
\hline \multicolumn{4}{|l|}{ Girls } \\
\hline Early-exit & 7,288 & 29.09 & 8.17 \\
\hline Late-exit & 5,333 & 30.13 & 8.17 \\
\hline
\end{tabular}

Language Learner girls in early-exit programs. Descriptive statistics for this analysis are presented in Table 3.

3.5. Reading Results for Grade 6. Regarding the 2009 school year, a statistically significant difference was not present in Grade 6 boys' TAKS Reading raw scores, $F(1,2374)=0.001$, $P=.98$, as a function of early-exit versus late-exit program. In addition, a statistically significant difference was not present in Grade 6 girls' TAKS Reading raw scores, $F(1,2188)=2.70$, $P=.10$, as a function of early versus late-exit program. The average TAKS Reading scores were similar for Grade 6 English Language Learner boys in the late-exit and earlyexit bilingual programs. Similarly, the average TAKS Reading scores were congruent for Grade 6 English Language Learner girls in late-exit and early-exit bilingual programs. Delineated in Table 4 are the descriptive statistics for this analysis.

With respect to the 2010 school year, a statistically significant difference was not present in Grade 6 boys' average TAKS Reading raw scores, $F(1,2456)=2.48, P=.12$, as a function of early-exit versus late-exit program. A statistically significant difference was present, however, for Grade 6 girls' average TAKS Reading raw scores, $F(1,2214)=3.84, P=.05$, partial $\eta^{2}=.002$, trivial effect size, as a function of early-exit versus late-exit program. Grade 6 English Language Learner boys in the late-exit and early-exit bilingual programs had commensurate average TAKS Reading raw scores. Grade 6
TABLE 4: Descriptive statistics for the 2009, 2010, and 2011 TAKS Reading scores for Grade 6 boys and girls by bilingual education program.

\begin{tabular}{|c|c|c|c|}
\hline $\begin{array}{l}\text { Year, gender, and bilingual } \\
\text { education program }\end{array}$ & $n$ & M & $\mathrm{SD}$ \\
\hline \multicolumn{4}{|l|}{2009} \\
\hline \multicolumn{4}{|l|}{ Boys } \\
\hline Early-exit & 1,005 & 28.46 & 8.99 \\
\hline Late-exit & 1,371 & 28.45 & 8.72 \\
\hline \multicolumn{4}{|l|}{ Girls } \\
\hline Early-exit & 881 & 28.75 & 8.24 \\
\hline Late-exit & 1,309 & 29.35 & 8.32 \\
\hline \multicolumn{4}{|l|}{2010} \\
\hline \multicolumn{4}{|l|}{ Boys } \\
\hline Early-exit & 1,003 & 27.11 & 9.85 \\
\hline Late-exit & 1,455 & 27.71 & 8.89 \\
\hline \multicolumn{4}{|l|}{ Girls } \\
\hline Early-exit & 874 & 28.51 & 8.98 \\
\hline Late-exit & 1,342 & 29.26 & 8.61 \\
\hline \multicolumn{4}{|l|}{2011} \\
\hline \multicolumn{4}{|l|}{ Boys } \\
\hline Early-exit & 965 & 27.01 & 10.04 \\
\hline Late-exit & 1,538 & 28.26 & 9.27 \\
\hline \multicolumn{4}{|l|}{ Girls } \\
\hline Early-exit & 871 & 28.72 & 9.44 \\
\hline Late-exit & 1,368 & 30.01 & 8.67 \\
\hline
\end{tabular}

English Language Learner girls in the late-exit program had higher average TAKS Reading raw scores than did Grade 6 English Language Learner girls in early-exit programs. Descriptive statistics for this analysis are presented in Table 4.

With respect to the 2011 school year, a statistically significant difference was yielded for Grade 6 boys' average TAKS Reading raw scores, $F(1,2501)=9.98, P=.002$, partial $\eta^{2}=$ .001 , trivial effect size, and for Grade 6 girls' average TAKS Reading raw scores, $F(1,2237)=11.08, P=.001$, partial $\eta^{2}=.005$, trivial effect size, as a function of early-exit versus late-exit program. Both Grade 6 English Language Learner boys and Grade 6 English Language Learner girls in the lateexit program had statistically higher average TAKS Reading scores than did Grade 6 English Language Learner boys and girls in the early-exit program. Presented in Table 4 ar e the descriptive statistics for this analysis.

3.6. Math Results for Grade 3. With respect to the 2009 school year for boys, a statistically significant difference was present for Grade 3 boys' TAKS Mathematics raw scores, $F(1,24466)=7.21, P=.007$, partial $\eta^{2}=.001$, trivial effect size, and for Grade 3 girls, $F(1,23639)=4.76, P=.029$, partial $\eta^{2}=.001$, trivial effect size, as a function of early-exit versus late-exit program. Grade 3 English Language Learner boys in late-exit programs had a lower average TAKS Mathematics raw score than did Grade 3 English Language Learner 
TABLE 5: Descriptive statistics for the 2009, 2010, and 2011 TAKS Mathematics scores for Grade 3 boys and girls by bilingual education program.

\begin{tabular}{lccc}
\hline $\begin{array}{l}\text { Year, gender, and bilingual } \\
\text { education program }\end{array}$ & $n$ & $\mathrm{M}$ & $\mathrm{SD}$ \\
\hline $\begin{array}{l}2009 \\
\text { Boys }\end{array}$ & & & \\
$\quad$ Early-exit & 14,991 & 31.10 & 7.30 \\
$\quad$ Late-exit & 9,477 & 30.84 & 7.36 \\
$\quad$ Girls & & & \\
$\quad$ Early-exit & 14,226 & 31.11 & 7.02 \\
$\quad$ Late-exit & 9,415 & 30.91 & 7.14 \\
2010 & & & \\
Boys & & & \\
$\quad$ Early-exit & 14,709 & 31.08 & 6.87 \\
$\quad$ Late-exit & 9,140 & 30.62 & 7.16 \\
Girls & & & \\
$\quad$ Early-exit & 13,698 & 30.89 & 6.89 \\
$\quad$ Late-exit & 8,873 & 30.82 & 6.79 \\
2011 & & & \\
Boys & & & \\
$\quad$ Early-exit & 14,905 & 31.28 & 6.90 \\
Late-exit & 7,301 & 31.46 & 6.74 \\
Girls & & & \\
$\quad$ Early-exit & & & \\
Late-exit & & 31.28 & 6.64 \\
\hline
\end{tabular}

boys in the early-exit program. Grade 3 English Language Learner girls in late-exit programs had a lower average TAKS Mathematics raw score than did Grade 3 English Language Learner girls in the early-exit program. Descriptive statistics for this analysis are presented in Table 5.

Concerning the 2010 school year for boys, a statistically significant difference was present in Grade 3 boys' average TAKS Mathematics raw scores, $F(1,23847)=24.89, P=$ .001 , partial $\eta^{2}=.001$, trivial effect size. A statistically significant difference was not present for Grade 3 girls, $F(1,22569)=0.45, P=.50$, as a function of early-exit versus late-exit program. Grade 3 English Language Learner boys had a statistically significantly lower average TAKS Mathematics raw score in late-exit programs than in early-exit programs. Grade 3 English Language Learner girls in both early-exit and late-exit bilingual programs had commensurate average TAKS Mathematics scores. Descriptive statistics for this analysis are presented in Table 5.

Regarding the 2011 school year, a statistically significant difference was not revealed in Grade 3 boys' TAKS Mathematics raw scores, $F(1,22200)=3.17, P=.08$, as a function of early-exit versus late-exit program. A statistically significant difference was present for Grade 3 girls' TAKS Mathematics raw scores, $F(1,21483)=16.26, P=.001$, partial $\eta^{2}=.001$, trivial effect size, as a function of early-exit versus late-exit program. Grade 3 English Language Learner boys in the late-exit and early-exit programs had commensurate TAKS
TABLE 6: Descriptive statistics for the 2009, 2010, and 2011 TAKS Mathematics scores for Grade 4 Boys and Girls by bilingual education program.

\begin{tabular}{|c|c|c|c|}
\hline $\begin{array}{l}\text { Year, gender, and bilingual } \\
\text { education program }\end{array}$ & $n$ & M & $\mathrm{SD}$ \\
\hline \multicolumn{4}{|l|}{2009} \\
\hline \multicolumn{4}{|l|}{ Boys } \\
\hline Early-exit & 11,435 & 31.95 & 8.79 \\
\hline Late-exit & 9,434 & 31.86 & 8.62 \\
\hline \multicolumn{4}{|l|}{ Girls } \\
\hline Early-exit & 10,474 & 32.18 & 8.38 \\
\hline Late-exit & 8,983 & 31.95 & 8.39 \\
\hline \multicolumn{4}{|l|}{2010} \\
\hline \multicolumn{4}{|l|}{ Boys } \\
\hline Early-exit & 11,798 & 32.57 & 7.89 \\
\hline Late-exit & 7,523 & 32.25 & 8.03 \\
\hline \multicolumn{4}{|l|}{ Girls } \\
\hline Early-exit & 10,634 & 32.40 & 7.91 \\
\hline Late-exit & 7,528 & 32.55 & 7.87 \\
\hline \multicolumn{4}{|l|}{2011} \\
\hline \multicolumn{4}{|l|}{ Boys } \\
\hline Early-exit & 12,017 & 32.52 & 8.18 \\
\hline Late-exit & 6,777 & 32.98 & 7.85 \\
\hline \multicolumn{4}{|l|}{ Girls } \\
\hline Early-exit & 10,878 & 32.44 & 8.11 \\
\hline Late-exit & 6,534 & 32.98 & 7.72 \\
\hline
\end{tabular}

Mathematics raw scores, whereas Grade 3 English Language Learner girls in the late-exit programs had a higher average TAKS Mathematics score than did Grade 3 English Language Learner girls in the early-exit program. Descriptive statistics for this analysis are presented in Table 5.

3.7. Math Results for Grade 4. Regarding the 2009 school year, a statistically significant difference was not present in Grade 4 boys' TAKS Mathematics raw scores, $F(1,20867)=0.65, P=$ .42. A statistically significant difference was yielded for Grade 4 girls' TAKS Mathematics raw scores, $F(1,19455)=3.72$, $P=.05$, partial $\eta^{2}=.001$, trivial effect size, as a function of early-exit versus late-exit program. Grade 4 English Language Learner boys in the early-exit and late-exit bilingual programs had comparable TAKS Mathematics scores. Grade 4 English Language Learner girls in late-exit programs had a lower average TAKS Mathematics raw score than did Grade 4 English Language Learner girls in early-exit programs. Descriptive statistics for this analysis are presented in Table 6.

With respect to the 2010 school year, a statistically significant difference was present in Grade 4 boys' TAKS Mathematics raw scores, $F(1,19319)=7.56, P=.006$, partial $\eta^{2}=.001$, trivial effect size, as a function of early-exit versus late-exit program. Grade 4 English Language Learner boys in late-exit bilingual programs had an average TAKS Mathematics raw score that was 0.32 points slightly lower than Grade 
4 English Language Learner boys in early-exit bilingual programs. A statistically significant difference was not present in Grade 4 girls' TAKS Mathematics raw scores, $F(1,18160)=$ $1.63, P=.20$, as a function of early-exit versus late-exit program. Descriptive statistics for this analysis are presented in Table 6.

With regard to the 2011 school year, a statistically significant difference was present in Grade 4 boys' TAKS Mathematics raw scores, $F(1,18792)=14.03, P=.001$, partial $\eta^{2}=.001$, trivial effect size, and in Grade 4 girls' TAKS Mathematics raw scores, $F(1,17410)=19.16, P=$ .001 , partial $\eta^{2}=.001$, trivial effect size, as a function of early-exit versus late-exit program. Grade 4 English Language Learner boys and girls in the late-exit bilingual programs had higher average TAKS Mathematics raw scores than did Grade 4 English Language Learner boys and girls in early-exit programs. Descriptive statistics for this analysis are presented in Table 6.

3.8. Math Results for Grade 5. Regarding the 2009 school year, a statistically significant difference was present in Grade 5 boys' TAKS Mathematics raw scores, $F(1,14650)=22.42$, $P=.001$, partial $\eta^{2}=.002$, trivial effect size, as a function of early-exit versus late-exit program. For Grade 5 girls, a statistically significant difference was not present, $F(1,13881)=$ $3.22, P=.07$, as a function of early-exit versus late-exit programs. Grade 5 English Language Learner boys in late-exit programs had a lower average TAKS Mathematics raw score than did Grade 5 English Language Learner boys in early-exit programs. Grade 5 English Language Learner girls in lateexit and early-exit bilingual programs had comparable TAKS Mathematics raw scores. Descriptive statistics for this analysis are presented in Table 7.

With respect to the 2010 school year, a statistically significant difference was present in Grade 5 boys' TAKS Mathematics raw scores, $F(1,15095)=8.75, P=.003$, partial $\eta^{2}=.001$, trivial effect size, as a function of early-exit versus late-exit program and in Grade 5 girls' average TAKS Mathematics raw scores, $F(1,13755)=6.56, P=.01$, partial $\eta^{2}=$ .001 , trivial effect size, as a function of early versus late-exit program. Grade 5 English Language Learner boys and girls in late-exit programs had a higher average TAKS Mathematics raw score than did Grade 5 English Language Learner boys and girls in early-exit programs. Descriptive statistics for this analysis are presented in Table 7.

For the 2011 school year, a statistically significant difference was present for Grade 5 boys' TAKS Mathematics raw scores, $F(1,13592)=13.20, P=.001$, partial $\eta^{2}=.001$, trivial effect size, as a function of early-exit versus late-exit program. A statistically significant difference was also yielded for Grade 5 girls' TAKS Mathematics raw scores, $F(1,12621)=89.45, P=.001$, partial $\eta^{2}=.007$, trivial effect size, as a function of early-exit versus late-exit program. Grade 5 English Language Learner boys and girls in late-exit bilingual programs had a higher average TAKS Mathematics raw score than did Grade 5 English Language Learner boys and girls in early-exit programs. Descriptive statistics for this analysis are presented in Table 7.
TABLE 7: Descriptive statistics for the 2009, 2010, and 2011 TAKS Mathematics scores for Grade 5 boys and girls by bilingual education program.

\begin{tabular}{|c|c|c|c|}
\hline $\begin{array}{l}\text { Year, gender, and bilingual } \\
\text { education program }\end{array}$ & $n$ & M & SD \\
\hline \multicolumn{4}{|l|}{2009} \\
\hline \multicolumn{4}{|l|}{ Boys } \\
\hline Early-exit & 7,622 & 31.68 & 9.09 \\
\hline Late-exit & 7,030 & 30.96 & 9.52 \\
\hline \multicolumn{4}{|l|}{ Girls } \\
\hline Early-exit & 7,016 & 31.68 & 8.68 \\
\hline Late-exit & 6,867 & 31.40 & 9.11 \\
\hline \multicolumn{4}{|l|}{2010} \\
\hline \multicolumn{4}{|l|}{ Boys } \\
\hline Early-exit & 7,844 & 30.19 & 10.56 \\
\hline Late-exit & 7,253 & 30.69 & 10.05 \\
\hline \multicolumn{4}{|l|}{ Girls } \\
\hline Early-exit & 7,033 & 29.85 & 10.42 \\
\hline Late-exit & 6,724 & 30.29 & 9.96 \\
\hline \multicolumn{4}{|l|}{2011} \\
\hline \multicolumn{4}{|l|}{ Boys } \\
\hline Early-exit & 8,118 & 30.35 & 10.41 \\
\hline Late-exit & 5,476 & 31.00 & 10.02 \\
\hline \multicolumn{4}{|l|}{ Girls } \\
\hline Early-exit & 7,289 & 29.38 & 10.48 \\
\hline Late-exit & 5,334 & 31.10 & 9.48 \\
\hline
\end{tabular}

3.9. Math Results for Grade 6. Regarding the 2009 school year, a statistically significant difference was not present in Grade 6 English Language Learner boys' TAKS Mathematics raw scores, $F(1,2376)=0.12, P=.73$, as a function of earlyexit versus late-exit program. In addition, a statistically significant difference was not present in Grade 6 English Language Learner girls TAKS Mathematics raw scores, $F(1,2190)=$ $2.11, P=.15$, as a function of early-exit versus late-exit program. Grade 6 English Language Learner boys and girls in late-exit and early-exit bilingual programs had comparable average TAKS Mathematics raw scores. Presented in Table 8 are the descriptive statistics for this analysis.

With respect to the 2010 school year, a statistically significant difference was present in Grade 6 boys' average TAKS Mathematics raw scores, $F(1,2457)=9.68, P=.002$, partial $\eta^{2}=.004$, trivial effect size, as a function of early-exit versus late-exit program. A statistically significant difference was not present in Grade 6 girls' average TAKS Mathematics raw scores, $F(1,2215)=0.87, P=.77$, as a function of early-exit versus late-exit program. Grade 6 English Language Learner boys in late-exit bilingual programs had a lower average TAKS Mathematics raw score than did Grade 6 English Language Learner boys in early-exit programs. Grade 6 English Language Learner girls in late-exit and early-exit bilingual programs had commensurate TAKS Mathematics raw scores. Descriptive statistics for this analysis are presented in Table 8. With respect to the 2011 school year, a statistically significant 
TABLE 8: Descriptive statistics for the 2009, 2010, and 2011 TAKS Mathematics scores for Grade 6 boys and girls by bilingual education program.

\begin{tabular}{|c|c|c|c|}
\hline $\begin{array}{l}\text { Year, gender, and bilingual } \\
\text { education program }\end{array}$ & $n$ & M & $\mathrm{SD}$ \\
\hline \multicolumn{4}{|l|}{2009} \\
\hline \multicolumn{4}{|l|}{ Boys } \\
\hline Early-exit & 1,005 & 31.13 & 9.25 \\
\hline Late-exit & 1,373 & 30.99 & 9.38 \\
\hline \multicolumn{4}{|l|}{ Girls } \\
\hline Early-exit & 883 & 31.16 & 8.88 \\
\hline Late-exit & 1,309 & 31.17 & 8.78 \\
\hline \multicolumn{4}{|l|}{2010} \\
\hline \multicolumn{4}{|l|}{ Boys } \\
\hline Early-exit & 1,004 & 32.30 & 9.39 \\
\hline Late-exit & 1,455 & 31.10 & 9.48 \\
\hline \multicolumn{4}{|l|}{ Girls } \\
\hline Early-exit & 875 & 31.73 & 9.28 \\
\hline Late-exit & 1,342 & 31.85 & 9.06 \\
\hline \multicolumn{4}{|l|}{2011} \\
\hline \multicolumn{4}{|l|}{ Boys } \\
\hline Early-exit & 965 & 31.88 & 9.40 \\
\hline Late-exit & 1,538 & 31.61 & 9.57 \\
\hline \multicolumn{4}{|l|}{ Girls } \\
\hline Early-exit & 871 & 31.56 & 9.02 \\
\hline Late-exit & 1,368 & 32.29 & 9.08 \\
\hline
\end{tabular}

difference was not yielded for Grade 6 boys' average TAKS Mathematics raw scores, $F(1,2501)=0.47, P=.49$, and for Grade 6 girls' average TAKS Mathematics raw scores, $F(1,2237)=3.43, P=.06$, as a function of early-exit versus late-exit program. Thus, Grade 6 English Language Learner boys and girls in late-exit and early-exit bilingual programs had comparable TAKS Mathematics raw scores. Revealed in Table 8 are the descriptive statistics for this analysis.

\section{Discussion}

In this empirical research investigation, two research questions were addressed in which the academic achievement of English Language Learner boys and girls in early-exit and late-exit bilingual programs for the 2008-2009, 2009-2010, and 2010-2011 school years was analyzed. To analyze the academic achievement of English Language Learners, data were obtained from the Texas Education Agency Public Education Information Management System. Specific data analyzed were the type of bilingual program enrollment, grade level, TAKS Reading, and TAKS Mathematics scores.

With respect to the TAKS Reading results for the 20082009 school year, English Language Learner boys in earlyexit bilingual education programs had higher scores in all four grades. In contrast, English Language Learner girls in late-exit bilingual education programs in all four grades had higher scores than English Language Learner girls in earlyexit bilingual education programs. In the 2009-2010 school year, English Language Learner boys in early-exit bilingual education programs had higher TAKS Reading scores in Grades 3 and 4. In contrast, English Language Learner boys in Grades 5 and 6 had higher TAKS Reading scores in late-exit bilingual education programs. English Language Learner girls in late-exit bilingual education programs had higher scores in all four grades than English Language Learner girls in early-exit bilingual education programs. Gardner and Desrochers [14] reported that females achieved higher levels of language proficiency than males. In regard to the 2010-2011 school year, English Language Learner boys and girls in lateexit bilingual education programs had higher TAKS Reading scores in all four grades. The TAKS Reading analyses were congruent with the literature $[14,16]$ in which girls acquired spoken language easier and faster and achieved higher levels of language proficiency than did boys.

Concerning the 2008-2009 school year, English Language Learner boys in early-exit bilingual education programs had higher TAKS Mathematics scores in all four grades, whereas English Language Learner girls in Grades 3, 4, and 5 had higher TAKS Mathematics scores in early-exit bilingual education programs. In Grade 6, however, English Language Learner girls had higher TAKS Mathematics scores in the late-exit bilingual education programs. Regarding the 20092010 school year, English Language Learner boys in early-exit programs had higher TAKS Mathematics scores in Grades 3, 4, and 6. However, English Language Learner boys in Grade 5 had higher TAKS Mathematics scores in late-exit bilingual education programs. English Language Learner girls in lateexit bilingual education programs had higher TAKS Mathematics scores in Grades 4, 5, and 6, whereas English Language Learner girls in Grade 3 early-exit bilingual education programs had higher TAKS Mathematics scores.

In regard to the 2010-2011 school year, English Language Learner boys in late-exit bilingual education programs had higher Mathematics scores in Grades 3, 4, and 5. English Language Learner boys in early-exit bilingual education programs had higher TAKS Mathematics scores in Grade 6. English Language Learner girls in late-exit bilingual education programs had higher TAKS Mathematics scores in all four grades. Consistent with the research literature $[3,10,11$, 23], English Language Learners in late-exit bilingual education programs outperformed English Language Learners in early-exit bilingual education programs in math.

In conclusion, our results were not supportive of either the early-exit or the late-exit bilingual education program as being more effective than its counterpart. Rather, our findings, when differences were present, were small to trivial, with regard to effect sizes. Moreover, our findings were inconsistent across grade level and across subject area. Accordingly, readers should be cautious about the extent to which they generalize from the results of this study. Further research is warranted, not only into examining the efficacy of transitional bilingual education programs, but also into one-way and 
two-way bilingual education programs. Given the increase in English Language Learners, not only in Texas but also across the United States, it is imperative that the efficacy of bilingual education programs be addressed.

\section{Conflict of Interests}

The authors declare that there is no conflict of interests regarding the publication of this paper.

\section{References}

[1] J. Rennie, ESL and Bilingual Program Models, ERIC Clearinghouse on Languages and Linguistics, Washington, DC, USA, 1993, http://www.ericdigests.org/1994/esl.htm.

[2] F. Tong, R. Lara-Alecio, B. Irby, P. Mathes, and O.-M. Kwok, "Accelerating early academic oral English development in transitional bilingual and structured English immersion programs," American Educational Research Journal, vol. 45, no. 4, pp. 10111044, 2008.

[3] V. P. Collier, "A synthesis of studies examining long-term language minority student data on academic achievement," Bilingual Research Journal, vol. 16, pp. 187-212, 1992.

[4] J. D. Ramirez, "Comparing structured English immersion and bilingual education: first-year results of a national study," American Journal of Education, vol. 95, no. 1, pp. 122-148, 1986.

[5] Y. Gallo, M. Garcia, L. Pinuelas, and I. Youngs, "Crisis in the southwest: bilingual education program inconsistencies," Multicultural Education, vol. 16, no. 2, pp. 10-17, 2008.

[6] F. Tong, B. J. Irby, R. Lara-Alecio, and P. G. Mathes, "English and Spanish acquisition by Hispanic second graders in developmental bilingual programs: a 3-year longitudinal randomized study," Hispanic Journal of Behavioral Sciences, vol. 30, no. 4, pp. 500529, 2008.

[7] G. Valdés, "Ethnolinguistic identity," in Bilingual Youth: Spanish in English-Speaking Societies, K. Potowski and J. J. Rothman, Eds., pp. 113-146, John Benjamins, Philadelphia, Pa, USA, 2011.

[8] J. Crawford, Bilingual Education: History, Politics, Theory, and Practice, Crane Publishing Company, Trenton, NJ, USA, 1989.

[9] L. Vygotsky, "The development of scientific concepts in childhood: the design of a working hypothesis," in Thought and Language, A. Kozulin, Ed., pp. 146-256, The Massachusetts Institute of Technology Press, Cambridge, Mass, USA, 1986.

[10] V. P. Collier, Acquiring a Second Language for School, vol. 1, National Clearinghouse for Bilingual Education, 1995, http:// www.google.com/url? sa $=t \& r c t=j \& q=\& e s r c=s \&$ source $=w e b \&$ $\mathrm{cd}=1 \& \mathrm{cad}=$ rja\&uact $=8 \& \mathrm{ved}=0 \mathrm{CCAQFjAA} \& \mathrm{url}=\mathrm{http} \% 3 \mathrm{~A} \% 2 \mathrm{~F}$ \%2Fhttp://www.usc.edu\%2Fdept\%2Feducation\%2FCMMR\% 2FCollierThomas_Acquiring_L2_for_School\&ei=EfaJVKbLAsOPyATswoKwCw\&usg=AFQjCNEFZYGXrArmeGsy8-TgYgZRcVz-g\&bvm=bv.81456516,d.aWw.

[11] J. Cummins, "Bilingual education and English immersion: the Ramirez report in theoretical perspective," Bilingual Research Journal, vol. 16, pp. 91-104, 1992.

[12] J. D. Ramirez, S. D. Yuen, and D. R. Ramey, "Final report: longitudinal study of structured English immersion strategy, earlyexit and late-exit transitional bilingual education programs for language-minority children, Vol. 1," Tech. Rep. 300-87-0156, Aguirre International, San Mateo, Calif, USA, 1991.

[13] C. Baker, Foundations of Bilingual Education and Bilingualism, Multilingual Matters, Bristol, UK, 5th edition, 2011.
[14] R. C. Gardner and A. Desrochers, "Second-language acquisition and bilingualism: research in Canada (1970-1980)," Research in Canada, vol. 22, pp. 146-162, 1981.

[15] P. Eckert and S. McConnell-Ginet, Language and Gender, Cambridge University Press, Cambridge, UK, 2003.

[16] D. A. Sousa, How the Brain Learns, Corwin, Thousand Oaks, Calif, USA, 4th edition, 2011.

[17] A. Cortez and R. L. Johnson, Bilingual Education in Texas, Intercultural Development Research Association, 2008, http://www.idra.org/IDRA_Newsletter/November_December_ 2008_Englightened_Public.

[18] Texas Education Agency, Limited English Proficiency Initiatives: Snapshots of ELLs in Texas, 2010, http://tea.texas .gov/index2.aspx?id=2906\&menu_id=949.

[19] Texas Education Agency, Language Proficiency Assessment Committee Framework Manual, 2012, http://portal.esc20.net/ portal/page/portal/doclibraryroot/publicpages/bilingualesl/ BESL\%20LPAC\%20Framework/Files/2012-2013LPAC_FrameworkManual.pdf.

[20] Texas Administrative Code, “Chapter 89. Adaptations for Special Populations Subchapter BB. Commissioner's Rules Concerning State Plan for Education English Language Learners," 2012, http://ritter.tea.state.tx.us/rules/tac/chapter089/ch089bb.html.

[21] A. Field, Discovering Statistics Using SPSS, Sage, Thousand Oaks, Calif, USA, 3rd edition, 2009.

[22] J. Cohen, Statistical Power Analysis for the Behavioral Sciences, Lawrence Erlbaum, Hillsdale, NJ, USA, 2nd edition, 1988.

[23] G. A. Cziko, "The evaluation of bilingual education from necessity and probability to possibility," Educational Researcher, vol. 21, pp. 10-15, 1992. 

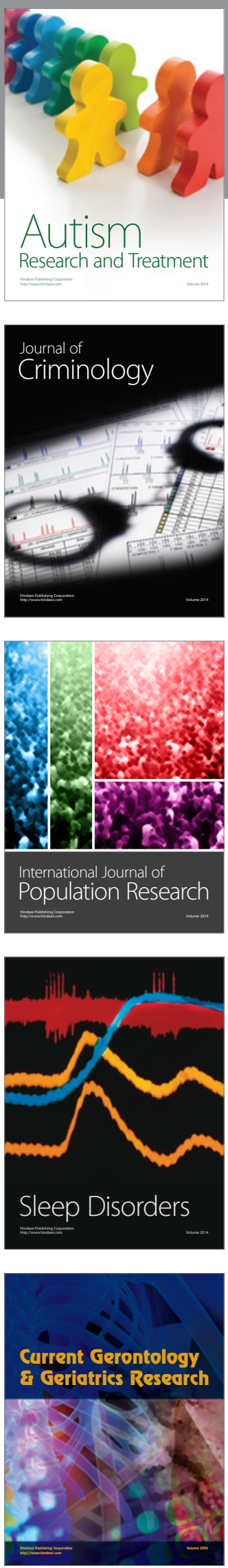
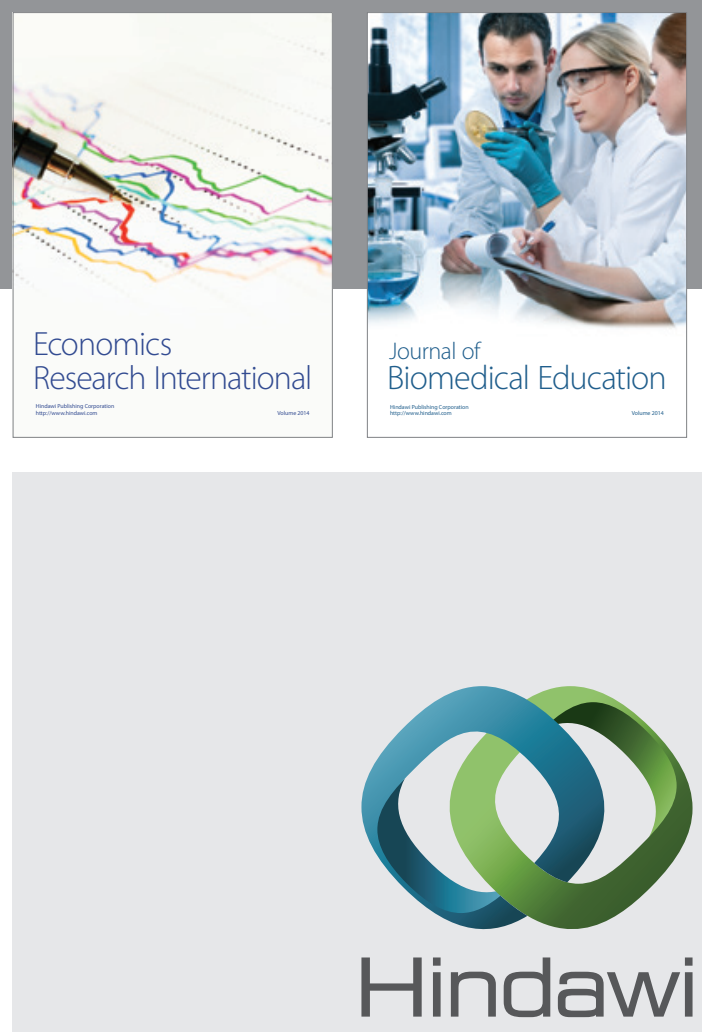

Submit your manuscripts at

http://www.hindawi.com
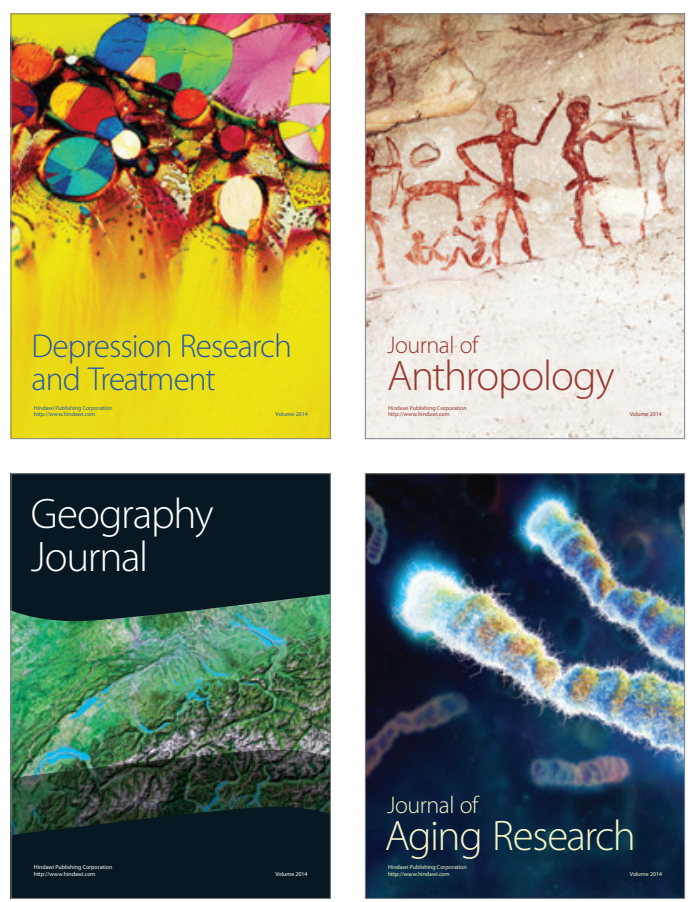
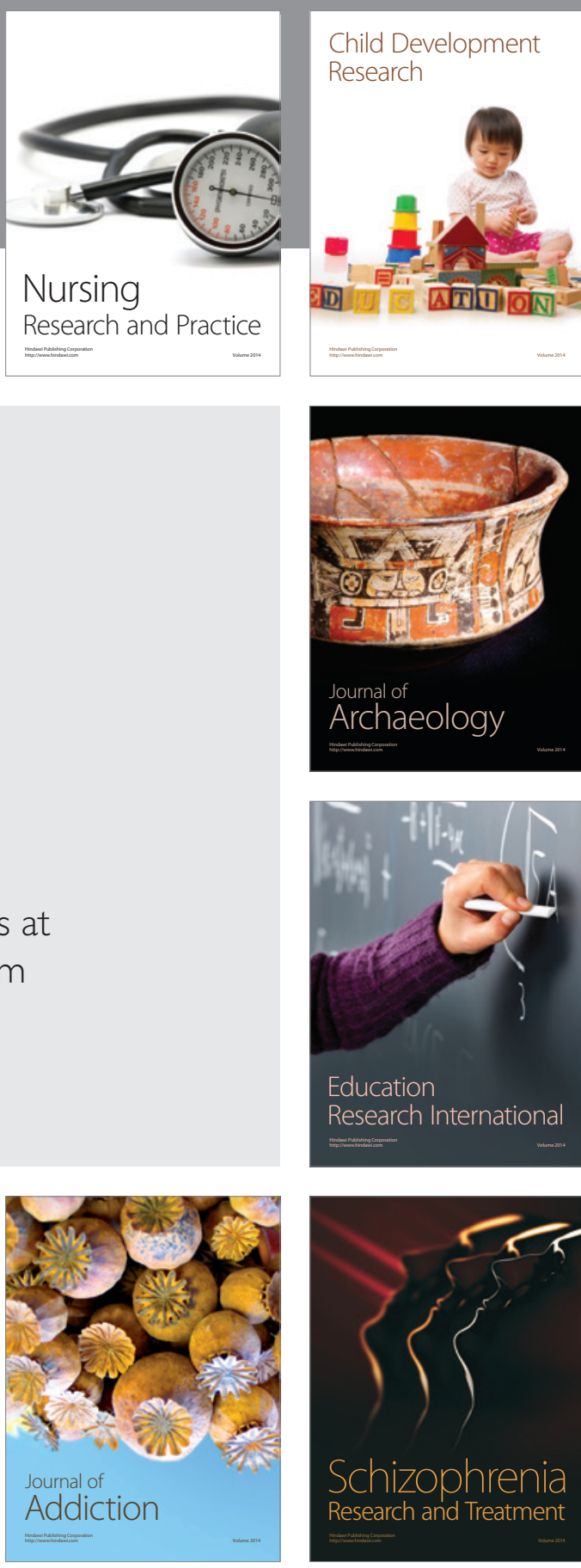

(D)
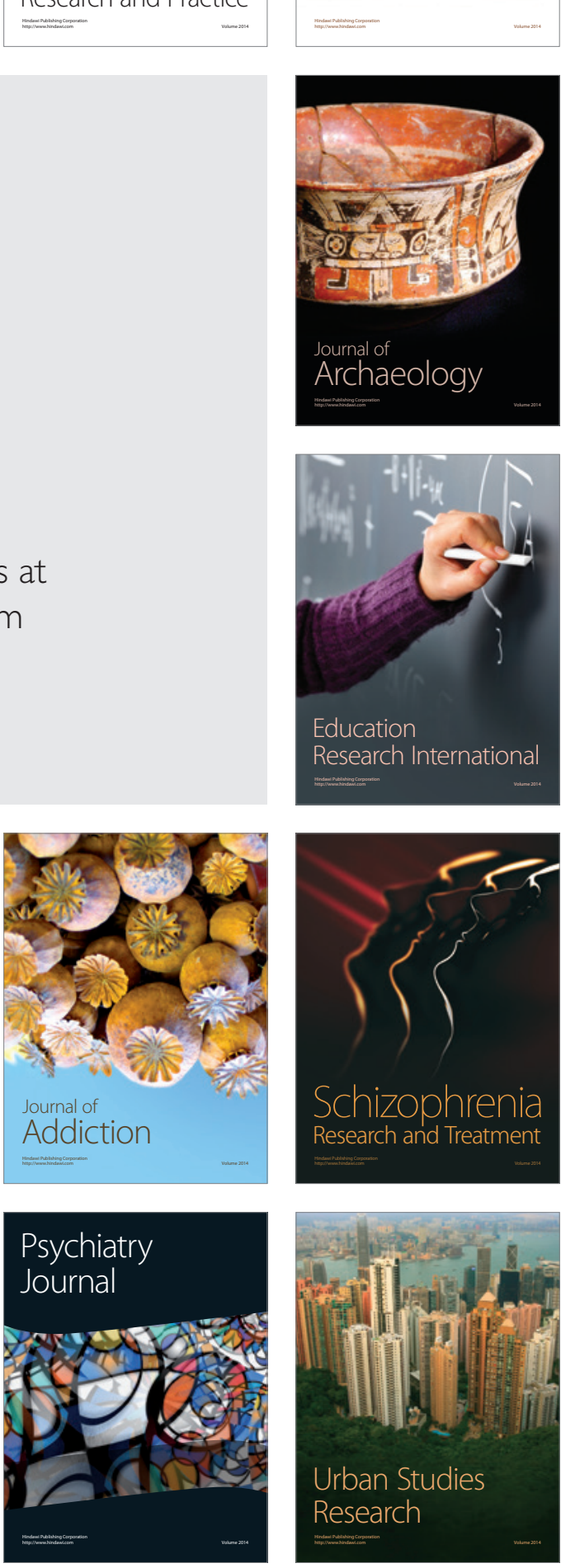